\title{
Painful left forearm swelling
}

\author{
Julio Brandão Guimaraes ${ }^{1,2,3}$ (D) Renato Masson ${ }^{2} \cdot$ Marcelo Petrilli $^{4} \cdot$ Maria Teresa de Seixas Alves $^{5}$. \\ Henrique Lederman ${ }^{1,2}$
}

Published online: 23 September 2020

(C) ISS 2020

A previously healthy 11-year-old boy presented to the emergency department with a history of left forearm pain. He described a 3-month history of intermittent mild left forearm pain, which worsened after activity. On physical exam, he presented swelling of the distal third of the left forearm, without signs of inflammation or infection. Figs. 1, 2 and 3.

The diagnosis can be found at https://doi.org/10.1007/s00256-02003591-w

Julio Brandão Guimaraes

Julio.BrandaoGuimaraes@ucsf.edu;

juliobrandaoguimaraes@hotmail.com

1 Department of Radiology, Grupo de Apoio ao Adolescente e à Criança com Câncer (GRAACC), Sao Paulo, Brazil

2 Department of Radiology, Federal University of Sao Paulo (UNIFESP), Sao Paulo, Brazil

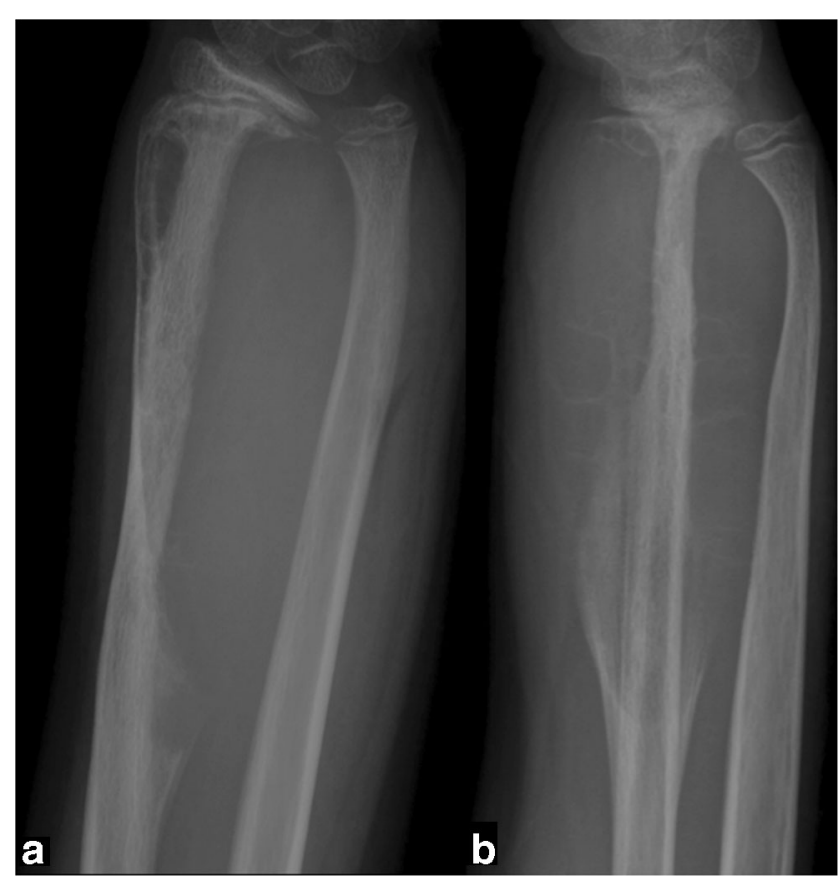

Fig. 1 CR

3 Musculoskeletal and Quantitative Imaging Research Group (MQIR), Department of Radiology and Biomedical Imaging, University of California, San Francisco, 185 Berry St, Suite 350, San Francisco, CA 94158, USA

4 Department of Orthopedic Surgery, Grupo de Apoio ao Adolescente e à Criança com Câncer (GRAACC), Sao Paulo, Brazil

5 Department of Pathology, Federal University of Sao Paulo (UNIFESP), Sao Paulo, Brazil 


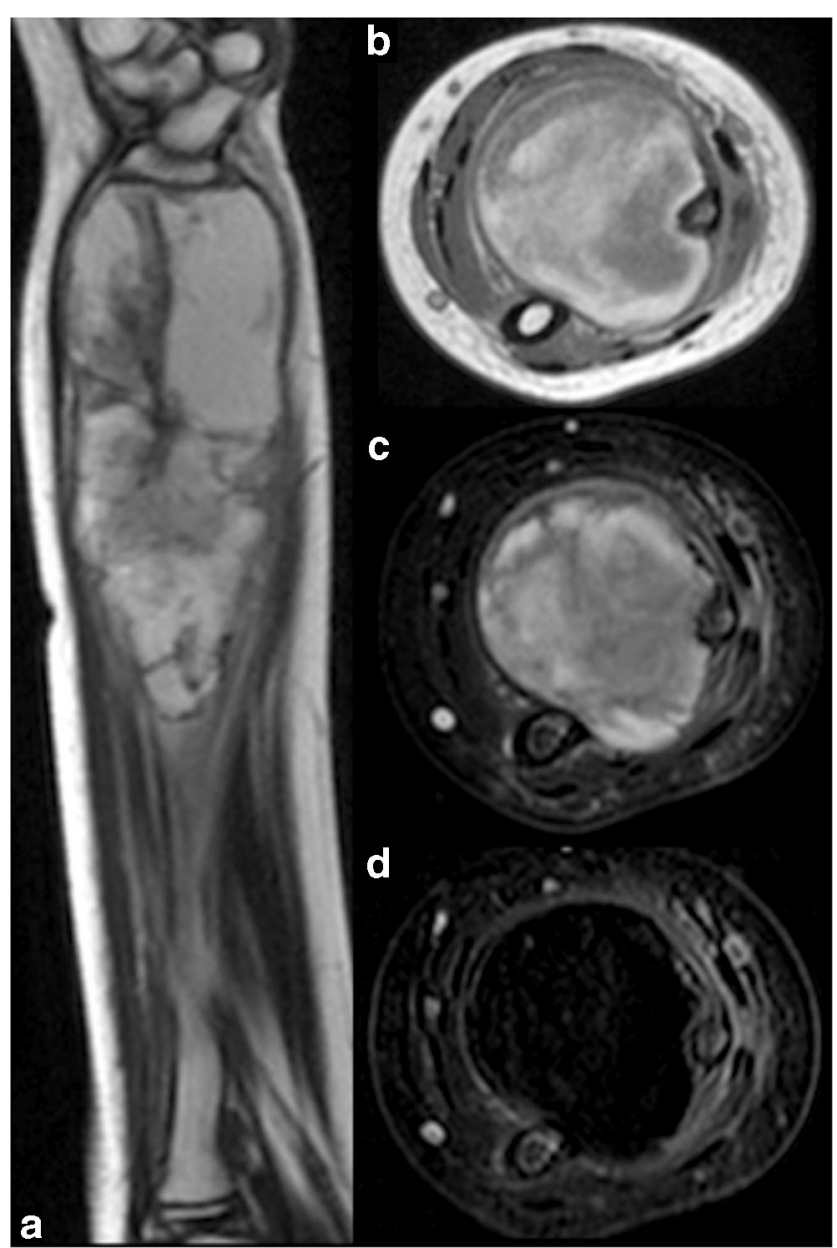

Fig. 2 MRI. a Sagittal T2-weighted FSE, b axial T1-weighted FSE, c axial T2-weighted fat-sat FSE, and $\mathbf{d}$ post-contrast subtraction

\section{Compliance with ethical standards}

Conflict of interest The authors declare that they have no conflict of interest.

Publisher's note Springer Nature remains neutral with regard to jurisdictional claims in published maps and institutional affiliations.

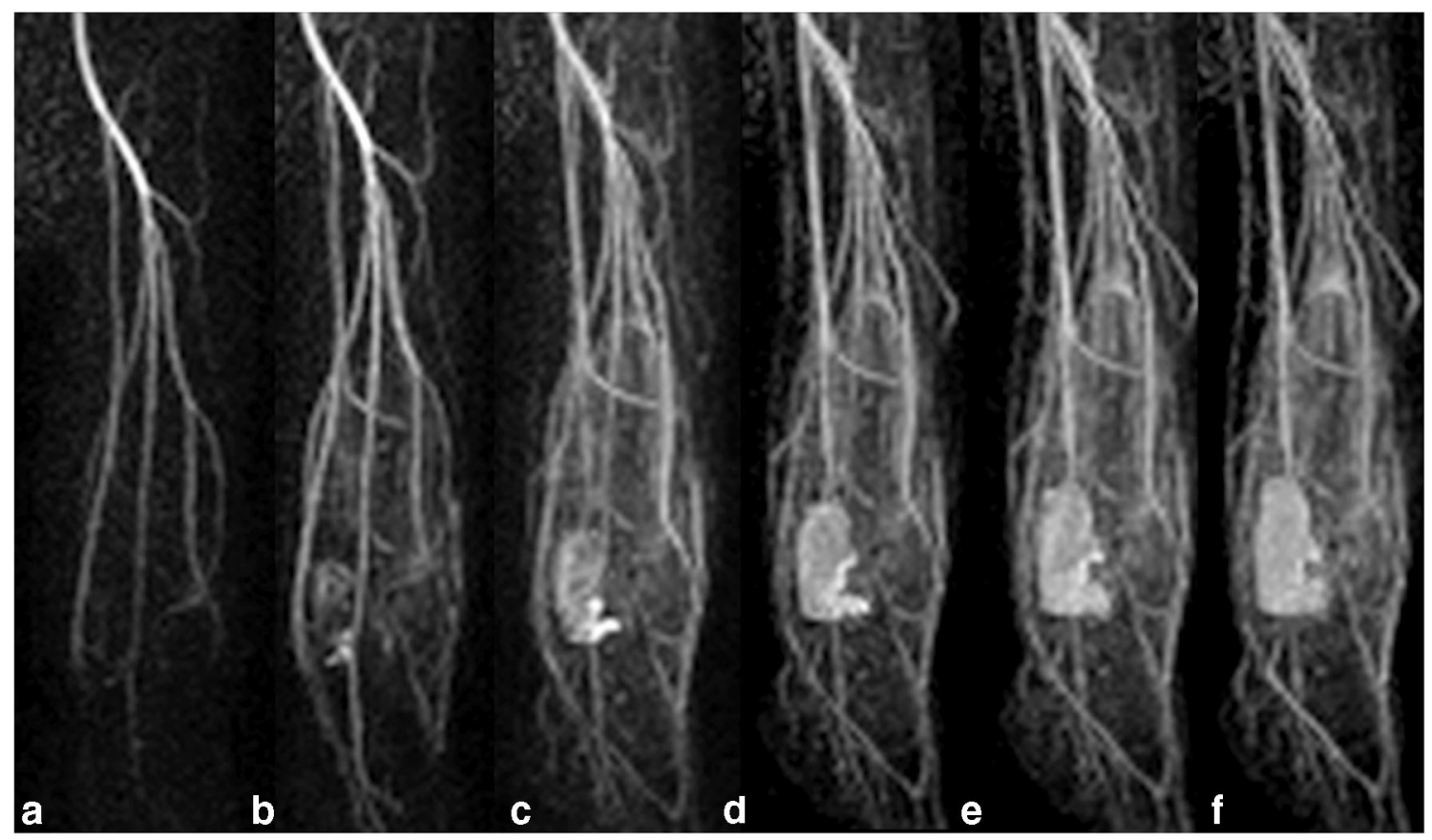

Fig. 3 Dynamic MR angiography 